\title{
МОЗГОВЫЕ ИНСУЛЬТЫ В ЭКОЛОГИЧЕСКИ НЕБЛАГОПРИЯТНЫХ ЗОНАХ ПРИАРАЛЬЯ
}

\begin{abstract}
Киличев И.А.*, Худойбергенов Н.Ю., Адамбаев 3.И.
Ургенчский филиал ТМА, Ургенч, Узбекистан

Мозговые инсульты в регионе Приаралья характеризуются преобладанием больных трудоспособного возраста (средний возраст 57 лет) и основными причинами всех форм мозговых инсультов является гипертоническая болезнь (58\%). Относительно высокий удельной вес геморрагических инсультов (4:1). Наиболее неблагоприятными месяцами в Ургенче для больных с цереброваскулярными заболеваниями являются: январь, февраль, март, май и декабрь, а критическими днями являются дни с III-IY типами погоды со спастическим и гипоксическим эффектами атмосферы. Ключевые слова: мозговые инсульты, ишемические и геморрагические инсульты, факторы риска, гипертоническая болезнь, атеросклероз, погодно-климатические факторы.
\end{abstract}

Сосудистая патология головного мозга, особенно вопросы их профилактики, является одной из актуальных проблем современной медицинской науки.

Для организации эффективной профилактики и успешной борьбы с цереброваскулярными заболеваниями большое значение имеет изучение их распространенности, частоты, смертности, и факторов риска. Одним из важных аспектов этой проблемы является изучение факторов риска мозгового инсульта. В настоящее время выделено несколько десятков факторов риска, одни из которых предрасполагают, а другие реализуют острое цереброваскулярное заболевание. Однако в этом ряду ведущее место отводится эндогенным факторам, а из экзогенных - чаще учитываются только социально-бытовые [3, 4, 6].

Между тем хорошо известно, что в совокупности факторов, влияющих на частоту мозговых инсультов, определенную роль играют климато-географические факторы $[1,2]$. Именно они, в отличие от других факторов риска, воздействуют в одинаковой мере на все субъекты, независимо от возраста, пола, социального статуса, исходных индивидуальных психобиологических особенностей организма. Реакция же организма в ответ на изменения климато-погодных условий зависит от адаптационных возможностей и реализуется через вегетативную нервную систему. Поэтому, в последние годы все большее значение придается факторам окружающей среды. Установлено, что в возникновении, течении и исходах мозговых инсультов существенную роль играют климатические условия. При *e-mail: qlichev@mail.ru этом отмечено, что влияние метеорологических факторов на организм строго специфично для каждого региона, так как каждый из них отличается своими климато-географическими особенностями. В последние годы подавляющее большинство исследователей признают влияние на организм не отдельных ингредиентов погоды, а всего сложного механизма метеорологического комплекса и его резких колебаний.

Цель исследования: изучить структуру заболеваемости и влияние комплекса погодноклиматических факторов на течение и исходы мозговых инсультов в экологически неблагоприятных зонах Приаралья.

Материал и методы. Для решения поставленной задачи нами проанализировано 427 больных с мозговыми инсультами (из них 174 выявлено во время регистра), принимавших стационарное лечение в Хорезмском филиале РНЦЭМП. Из них мужчин было 236 (55,2\%), женщин - 191 (44,8\%). Средний возраст больных составил 57,3 лет (у мужчин 56,7 а у женщин - 58,2).

Сведения о погодных факторах по г.Ургенчу за 2012 год было получено из метеостанции г.Ургенча. Известно, что в естественных условиях на организм виляют не отдельные метеофакторы, а весь комплекс климато- погодных факторов. Поэтому для изучения влияния климато-погодных факторов использовали морфодинамические классификации погоды И.И.Григорьева в соавт. (1974г). Все разнообразия погодных условий по сумме и динамике барико-циркуляционных, электрометеорологических и гелиогеофизи- 
ческих показателей, классифицированы в четырех медицинских типах погоды: из которых I и II типы в метеопатологическом отношении относятся к благоприятным типам погоды, a III и IV типы - к неблагоприятным.

При изучении влияния различных эффектов атмосферы использовали классификацию В.Ф.Овчаровой.

На основании многолетних исследований В.Ф.Овчаровой с учетом характера изменения и сочетания метеорологических факторов, а также атмосферных циркуляций, разработаны следующие метеорологические эффекты атмосферы:

- гипотензивный - при разрушении антициклона, приближении теплового атмосферного фронта;

- гипоксический - при установлении области низкого атмосферного давления в зоне теплого атмосферного фронта (циклон, ложбина, БОНД);

- тонизирующий - при приближении холодного атмосферного фронта;

- спастический - при установлении области высокого атмосферного давления в зоне высокого атмосферного фронта (гребень, отрог, БОНД);

- сочетание нескольких эффектов при сочетании теплого и холодного атмосферного фронтов.

Результаты. Для получения более достоверных данных о структуре заболеваемости мозговыми инсультами нами в 2012 г. (с 1.01.12 г. по 31. 12.12 г. включительно) в г. Ургенче (Хорезмский вилоят) проведен ре- гистр мозгового инсульта.

Регистрации подлежали все новые и повторные случаи мозгового инсульта, развившиеся в период наблюдения у постоянных жителей изучаемого района, независимо от возраста и пола заболевшего.

За год исследования среди жителей Ургенча (136664 чел. 2012г) выявлено 174 новых случаев мозгового инсульта (включая повторные у одних и тех же больных), серди них $88(45,8 \%)$ мужчин и $86(54,2 \%)$ женщин. Средний возраст больных составил 57,3 лет (у мужчин - 56,7 лет, у женщин - 58,2).

Причиной острых нарушений мозгового кровообращения в 58\% случаев была гипертоническая болезнь, в 15,2\% - атеросклероз сосудов головного мозга, в 15,8\% - сочетания атеросклероза церебральных сосудов с гипертонией, в $11 \%$ - ревмаваскулит, аневризмы сосудов головного мозга, сахарный диабет и др.

Анализ случаев мозговых инсультов в зависимости от характера нарушений мозгового кровообращения показал, что инфаркт мозга был у 142 (81\%) больных, кровоизлияние в мозг - у 28 (16\%) субарахноидальное кровоизлияние - у 4 (3\%).

Частота всех случаев мозгового инсульта на 1000 населения составила 1,27; а на 1000 взрослого населения (старше 20 лет) - 1,99. Анализ общей частоты случаев мозгового инсульта показал, что как среди мужчин, так и среди женщин отмечено статистически достоверный $(\mathrm{P}<0,01)$ рост заболеваемости в возрастных группах 45-49 лет и 60-74 лет по сравнению с другими возрастными группами (Табл.1).

Табл. 1

Среднегодовая заболеваемость населения г.Ургенча мозговыми инсультом в 2012г (на 1000 жителей в год)

\begin{tabular}{|c|c|c|c|}
\hline Возрастная группа & Мужчины & Женщины & Оба пола \\
\hline $15-29$ & $0-0$ & $0-0$ & 0 \\
\hline $30-44$ & 0,33 & 0,06 & 0,19 \\
\hline $45-59$ & 3,51 & 2,26 & 2,86 \\
\hline $60-74$ & 11,53 & 11,51 & 11,52 \\
\hline 75 и старше & 23,65 & 9,62 & 15,55 \\
\hline 20 и старше & 2,01 & 1,92 & 1,99 \\
\hline Все населения & 1,32 & 1,15 & 1,27 \\
\hline
\end{tabular}


Заболеваемость мозговыми инсультами у мужчин выше, чем у женщин во всех возрастных группах.

Изучение заболеваемости населения в зависимости от характера мозговых инсультов показало, что средняя годовая заболеваемость ишемическим инсультом (1,03 случая на 1000 жителей в год) была в 5,1 раз выше заболеваемости кровоизлияния в мозг $(0,2)$, и в 51 раз выше заболеваемости субарахноидального кровоизлияния $(0,02)$.

Для более детального изучения структуры, факторов риска и сезонности мозговых инсультов нами проанализировано 253 историй болезни больных с мозговыми инсультами, принимавших стационарное лечение в Хорезмском филиале РНЦЭМП в 2012-2013 гг. Из них мужчин было 148 (58,5\%), женщин 105 (41,5\%). Средний возраст больных соста- вил 57,3 лет (у мужчин - 56,7 а у женщин $58,2)$.

Исследование показало, что наибольшее число больных было в возрасте от 60 до 74 лет $(43,4 \%)$ и от 45 до 59 лет $(40 \%)$, больные в трудоспособном возрасте (от 20 до 59 лет) составили 52,6\% (Табл.2).

Анализ, проведенный в зависимости от возраста больных показал, что гипертоническая болезнь чаще наблюдалась у больных в возрасте от 45 до 59 лет $(54,0 \%)$ и преобладала в трудоспособном возрасте (от 20 до 59 лет) $68,3 \%$.

Атеросклероз и его сочетания с гипертонией преимущественно наблюдались в возрастной группе от 60 до 74 лет (соответственно $82,0 \%$ и 80,3$)$ и число больных ими преобладало в возрастных группах старше 60 лет (соответственно: 90,6\% и 94,5\%).

Табл. 2

\section{Распределение больных с МИ в г.Ургенче по возрастам в зависимости от причины заболевания}

\begin{tabular}{|c|c|c|c|c|c|c|c|c|c|c|}
\hline \multirow{3}{*}{$\begin{array}{c}\text { Причины } \\
\text { заболевания }\end{array}$} & \multicolumn{8}{|c|}{ Возраст в годах } & \multicolumn{2}{|c|}{ Всего } \\
\hline & \multicolumn{2}{|c|}{ До 44 лет } & \multicolumn{2}{|c|}{$\begin{array}{c}\text { От } 45 \text { до } 59 \\
\text { лет }\end{array}$} & \multicolumn{2}{|c|}{$\begin{array}{c}\text { От } 60 \text { до } 74 \\
\text { лет }\end{array}$} & \multicolumn{2}{|c|}{$\begin{array}{c}\text { От } 75 \text { до } 90 \\
\text { лет }\end{array}$} & \multirow{2}{*}{$\begin{array}{l}\text { Абс. } \\
\text { чис } \\
\text { ло }\end{array}$} & \multirow[t]{2}{*}{$\%$} \\
\hline & $\begin{array}{c}\text { Абс.ч } \\
\text { ис }\end{array}$ & $\%$ & $\begin{array}{c}\text { Абс.ч } \\
\text { ис }\end{array}$ & $\%$ & $\begin{array}{l}\text { Абс. } \\
\text { чис }\end{array}$ & $\%$ & $\begin{array}{l}\text { Абс. } \\
\text { чис }\end{array}$ & $\%$ & & \\
\hline $\begin{array}{l}\text { Гипертоничес- } \\
\text { кая болезнь }\end{array}$ & 21 & 14,7 & 78 & 53,7 & 46 & 31,6 & - & - & 145 & 57,3 \\
\hline Атеросклероз & - & - & 4 & 10,3 & 32 & 82,0 & 3 & 7,7 & 39 & 15,4 \\
\hline $\begin{array}{l}\text { Гипертоничес- } \\
\text { кая болезнь в } \\
\text { сочетании с } \\
\text { атеросклерозом }\end{array}$ & - & - & 2 & 5,0 & 33 & 80,3 & 6 & 14,7 & 41 & 16,2 \\
\hline Прочие & 11 & 39,3 & 17 & 60,7 & - & - & - & - & 28 & 11,1 \\
\hline Всего & 32 & 12,7 & 101 & 39,9 & 111 & 43,8 & 9 & 3,6 & 253 & 100 \\
\hline
\end{tabular}

У мужчин мозговые инсульты чаще наблюдаются в возрасте от 45 до 59 лет $(43,5 \%)$, а в трудоспособном возрасте (до 59 лет) составили $55,9 \%$.

У женщин большинство больных были в возрасте от 60 до 74 лет $(46,8 \%)$ и преобладало число больных старше 60 -летного возраста $-52,6 \%$.

Дальнейшее изучение показало, что гипертоническая болезнь являлась причиной кровоизлияния в мозг в 72,3\% случаях, субарах- ноидального кровоизлияния мозг - в 64,7\%, инфаркта мозга - в 55,3\%. Атеросклероз церебральных сосудов, в основном, служил причиной инфаркта мозга в $18,6 \%$, его сочетание с гипертонией наблюдалось при субарахноидальном кровоизлиянии в $23,5 \%$, кровоизлиянии мозг - в 19,2\%, при инфаркте мозга - в 14,8\%.

Инфаркт мозга чаще наблюдали в возрастных группах от 45 до 59 лет и от 60 до 74 лет (соответственно 41,5\% и 41,5\%) и число слу- 
чаев преобладало у больных в возрасте до 59 лет $(54,4 \%)$. Кровоизлияние в мозг и субарахноидальное пространство чаще отмечалось в возрасте от 60 до 74 лет (соответственно $51,1 \%$ и $58,8 \%$ и число больных преобладала в возрасте старше 60 лет (соответственно $53,2 \%$ и $58,8 \%$ ).

На основании изменчивости основных метеорологических факторов (температура воздуха, атмосферное давление, скорость ветра, относительная влажность) мы определили типы погоды и эффекты атмосферы. Нами выявлено, что в Ургенче за 2012 год отмечено 172 дней с неблагоприятными типами (III-IY) погоды.

Изучение возникновения мозговых инсультов в зависимости от типов погоды выявили, что заболеваемость достоверно $(0,05)$ выше в дни с III-IY типами погоды $(1,4)$ (Табл.3.).

Для определения частоты встречаемости дней неблагоприятных по типам погоды, ежемесячных и сезонных, мы проводили их ежемесячный анализ. При этом установили, что наибольшее число неблагоприятных дней было в январе - 17 , феврале - 21, марте - 23, мае - 16 и декабре - 19.

Как отмечено выше (Табл.3) 65\% (240) случаев мозгового инсульта произошло в дни с неблагоприятными типами (III и IY типы) погоды. При распределении числа случаев мозгового инсульта по месяцам, в зависимости от даты развития их, установлено, что наиболее высокий процент заболеваемости наблюдается в январе $14,5 \%$, феврале - 10\%, марте $11,0 \%$, мае - $11 \%$ и декабре - 9\%, а наименьшие показатели в июне - 3\% и ноябре - 4,6\%.

Табл.3.

\section{Среднесуточные показатели заболеваемости мозговыми инсультами в зависимости от типов погоды}

\begin{tabular}{|c|c|c|}
\hline \multirow{2}{*}{ Дни } & \multicolumn{2}{|c|}{ Типы погоды } \\
\cline { 2 - 3 } & I-II & III-IY \\
\hline Число случаев мозговых инсультов & 119 & 240 \\
\hline Число дней с & 203 & 172 \\
\hline различными типами погоды & & $1,4+0,03$ \\
\hline Среднесуточные показатели & $0,6+0,02$ & \\
\hline Р1:2 & $<0,05$ & \\
\hline
\end{tabular}

В соответствии с поставленной задачей мы сопоставляли показатели ежемесячного распределения числа случаев мозгового инсульта с показателями неблагоприятных дней (дни с III и IY типами погоды). При этом выявили, что динамики числа случаев мозгового инсульта по месяцам почти совпадает с динамикой числа дней с III и IY типами погоды. Например: увеличение числа случаев мозгового инсульта в январе $(14,5 \%)$, феврале $(10 \%)$, марте $(11,0 \%)$, мае $(11 \%)$ и декабре $(9 \%)$ соответствуют увеличению числу дней с III и IY типами погоды в эти месяцы (соответственно в январе - 17, феврале - 21, марте - 23, мае - 16 и декабре - 19).

Необходимо отметить, что некоторое увеличение заболеваемости в июле и августе, возможно, связаны с гипоксическим эффектом атмосферы. Как известно для Хорезмской области в летнее время характерно возникновение термический депрессии. Для такого синоптического состояния характерно сочетание очень высокой температуры (до $30^{\circ} \mathrm{C}$ и выше утром и до $40-45^{\circ} \mathrm{C}$ днем), чрезвычайно низкой влажности и низкого атмосферного давления, которые обусловливают гипертермическую и гипобарическую гипоксию. Например: с 18/YII-2012 г. по 19/YII 2012 в городе Ургенче температура воздуха была $+39-41^{\circ} \mathrm{C}$, относительная влажность 40 $43 \%$ и атмосферное давление 746 м бар. За эти 2 дня отмечено 2 случая мозгового инсульта.

Дальнейший анализ 172 неблагоприятных дней (III-IY типы), в зависимости от характе- 
ра изменения метеорологических факторов и их сочетания показало, что 11 (6,4\%) дня были с гипотензивным эффектом атмосферы, 84 $(48,7 \%)$ - гипоксическим, 69 (40,3\%) - спастическим и $8(4,6 \%)$ - тонизирующим.

Анализ заболеваемости мозговыми инсультами в зависимости от эффектов атмосферы показал, что среднесуточные показатели заболеваемости мозговыми инсультами достоверно выше при спастическом $(1,47)$ и гипоксическом $(1,42)$ эффектах атмосферы. При этом наиболее низкие показатели отмечены при тонизирующем $(0,9)$ эффекте атмосферы.

При изучение влияние эффектов атмосферы на частоту возникновении мозговых инсультов в зависимости от их причин, установлено, что мозговые инсульты, как при гипертонической болезни, так и при атеросклерозе церебральных сосудов чаще наступали при спастическом и гипоксическом эффектах атмосферы.

На основании данных литературы $(1,2)$ и результатов наших исследований можно представить следующие пути развития метеотропных реакций. Первый из них заключается в том, что неблагоприятные изменения погоды вызывают комплекс специфических и неспецифических сдвигов в организме людей, не страдающих какими-либо острыми или хроническими болезнями. В этом случаев метеорологические факторы выступают в роли основной причины страдания, при этом можно говорить о метеотропной болезни или ме-

\section{ЛИТЕРАТУРА}

1. Андронова Т.И., Деряпа Н.Р., Соломатин А.П. Гелиометеотропные реакции здорового и больного человека.- Л: Медицина, 1982-246 с.

2. Ассман Д. Чувствительность человека и погода Л.Гидрометеоиз-дат, 1986-248 с.

3. Гафуров Б.Г., Аликулова Н.А., Лукашевич А.Л. и др. Клиническая структура мозговых инсультов в отдельных регионах Республики Узбекистан по материалам анализа "Регистра мозгового инсульта" / Неврология.-2000.-№ 2.-С.6-8.

4. Гусев Е.И., Скворцова В.И., Стаховская Л.В. Эпидемиология инсульта в России // Журн. неврологии и теотропной реакции. Второй путь состоит в том, что под влиянием изменений погоды симптомы заболевания или патологические процессы, которые уже существуют у больных, усиливаются или проявляются (манифестация патологических процессов). Третий путь - это физиологическая адаптация к непривычным климатическим факторам, то есть процесс, связанный с выработкой нового стереотипа внутренних реакций.

\section{Выводы}

1. Мозговые инсульты в регионе Приаралья характеризуются преобладанием больных трудоспособного возраста и основными причинами всех форм мозговых инсультов является гипертоническая болезнь.

2. Из всех форм инсультов преобладает ишемический и он чаще наблюдаются в трудоспособном возрасте, а геморрагический после 60 лет.

3. Увеличение числа мозговых инсультов и возникновение метеорологических реакций в дни с III-IV типами погоды являются результатом влияния на организм не отдельных факторов, а всего комплекса погодно-климатических условий.

4. Наиболее неблагоприятными месяцами в Ургенче для больных с цереброваскулярными заболеваниями являются: январь, февраль, март, май и декабрь, а критическими днями являются дни с III-IV типами погоды со спастическим и гипоксическим эффектами атмосферы.

психиатрии им. С.С.Корсакова.-2003.-Вып.8 -С.4-9. (Инсульт: приложение к журн.)

5. Рахимбаева Г.С., Мусаева Ю.А., Курамбаева С.Р., Кусаева Д.М. Особенности этиологии и диагностики ишемического инсульта у молодых пациентов //Неврология.-2010.- № 4.-С.119.

6. Суслина 3.А. Сосудистые заболевания головного мозга: Эпидемиология. Патогенетические механизмы. Профилактика / 3.А.Суслина, Ю.Я.Варакин, Н.В.Верещагин.- 2-е изд., доп и перераб.- М.: Медпресс-информ, 2009.- $352 \mathrm{c}$. 


\title{
XÜLASə
}

\section{ARALӨTRAFI REGIONUN EKOLOJI OLVERISSSIZZ ZONALARINDA BEYIN İNSULTLARI}

\author{
Kilichev İ.A., Xudoybergenov N.Yu., Adambaev Z.í. \\ Daşkənt tibb akademiyasinin Urgenc filiall, Urgenc, Özbəkistan
}

Aralyanı regionda beyin insultları əməkqabiliyyətli əhali arasında (orta yaş 57) daha çox rast gəlinməklə və bütün formalarının əsas səbəbi hipertoniya xəstəliyi olmaqla xarakterizə olunur (58\%). Hemorragik insultlarım xüsusi çəkisi nisbətən yüksək olmuşdur (4:1). Urgencdə serebrovaskulyar xəstəliklərdən əziyyət çəkənlər üçün ən əlverişsiz ay: yanvar, fevral, mart, may və dekabr olmuşdur, kritik günlər isə atmoxferin spastik və hipoksik effektli hava şəraitində III-IV günlər olmuşdur.

Açar sözlər: beyin insultları, işemik və hemorragik insultlar, hipertoniya xəstəliyi, ateroskleroz, hava-iqlim amili.

\section{SUMMARY}

\section{STROKES IN ECOLOGIAL DISADVANTAGE ZONE ARAL SEE}

\author{
Kilichev I.A., Hudayberganov N.Y., Adambaev Z.I. \\ Urgench branch of Tashkent Medical Academy, Urgench, Uzbekistan
}

Strokes in region Aral See are characterized by prevalence of the sick able-bodied age (the average age 57 years) and the main reason of all forms of Strokes is hypertension disease (58\%). Comparatively high specific gravity hemorrhagic stroke (4:1). The most disadvantage month in Urgenche for sick with serebrovasculary diseases are: January, February, March, May and December, and critical days are a days with III-IY types of the weather with spastic and hypoxic effects of atmosphere.

Keywords: stroke, ischemic and hemorrhagic stroke, factors of the risk, hypertension disease, arthroscleroses, the waited-climatic factors.

Redaksiyaya daxil olub: 05.08.2015

Çapa tövsiya olunub: 25.08 .2015

Rayçi: t.ü.f.d. Hasənov X.I. 